\title{
Diagnóstico Ambiental de Cursos d'água Tributários da Bacia Hidrográfica do Rio Paranapanema nos Estados de São Paulo e Paraná
}

\section{Environmental Diagnosis of Urban Streams in Paranapanema River Hydrographic Basin from São Paulo and Parana States}

\author{
Armando Castello Branco Jr. ${ }^{1}$; Ana Amábile Borda ${ }^{2}$; Camila da Silva ${ }^{3}$; \\ Gessica Loanda Silva ${ }^{4}$; Maria Fernanda Rizzo \\ ${ }^{1}$ Professor da Universidade Federal do Triângulo Mineiro (UFTM), Campus de Iturama, Minas Gerais, Brasil. \\ Orcid: orcid.org/0000-0002-2848-1649. E-mail: armando.junior@uftm.edu.br \\ ${ }^{2}$ Aluna do Curso de Pós-Graduação em Engenharia Civil e Ambiental, Universidade Estadual Paulista "Julio de Mesquita \\ Filho" (UNESP), Bauru, São Paulo, Brasil. E-mail: aa_borda@hotmail.com \\ ${ }^{3}$ Bióloga da Ecobio Assessoria Ambiental, Santo Antônio da Platina, Paraná, Brasil. E-mail: camilasilva89@ymail.com \\ ${ }^{4}$ Bióloga da Prefeitura Municipal de Jundiaí do Sul, Vigilância Sanitária, Jundiaí do Sul, Paraná, Brasil. \\ E-mail: gessicaloanda@gmail.com \\ ${ }^{5}$ Bióloga, Faculdades Integradas de Ourinhos (FIO), Ourinhos, São Paulo, Brasil. E-mail: mf-rizzo@bol.com.br
}

\begin{abstract}
RESUMO: Embora os comitês de bacias hidrográficas realizem relatórios periódicos sobre a qualidade das águas, as análises são baseadas em amostragem nos cursos d'água de maior volume não refletindo a realidade dos mananciais menores, especialmente os que atravessam áreas urbanas de pequenos municípios ou que estejam próximos à área urbana. Objetivou-se realizar o diagnóstico ambiental de mananciais com base em critérios físico-químicos, microbiológicos e ecológicos. Dessa forma, não apenas a qualidade das águas mas o atendimento ao enquadramento legal para seus usos foram investigados além da influência antrópica sobre os mananciais. Este estudo foi realizado em 7 cursos d'água da Bacia Hidrográfica do rio Paranapamena em 4 municípios: Santo Antônio da Platina e Jundiaí do Sul, na bacia do Rio das Cinzas, no Norte Pioneiro do Paraná e; Fartura e Ipaussu, ambos tributários da bacia do Alto Paranapanema no Estado de São Paulo. Foram demarcadas estações de amostragem de água em cada manancial para avaliação físico-química e microbiológica. Foram verificados temperatura, oxigênio dissolvido, dureza, amônia, ferro, fosfato, $\mathrm{pH}$, turbidez e cloreto por meio de kit colorimétrico de campo. A análise microbiológica foi feita pela técnica de disseminação com meios de cultura Agar-Nutriente e MacConkey. O impacto da atividade antrópica nos mananciais foi investigado pela aplicação de protocolo de avaliação ecológica rápida. Os resultados mostraram o não atendimento a vários parâmetros legais para cursos d'água Classe 2 ( $\mathrm{pH}$, oxigênio dissolvido, cloretos, amônia, fosfato e ferro) e a possibilidade de risco a saúde humana e à preservação das comunidades aquáticas. Foram revelados diferentes níveis de interferência humana e correlações entre parâmetros de qualidade d água.
\end{abstract}

PALAVRAS-CHAVE: Recursos hídricos; Qualidade de água; Avaliação ecológica rápida; Gestão ambiental.

ABSTRACT: The periodic reports of water quality from Hydrographic Basin Committees do not reflect the real state of springs, specially those ones crossing or nearby urban areas in small cities. The aim of the present work is to undertake the environmental diagnosis of streams investigating the water quality and the urban anthropic impact on these streams. This work was realized in 6 different streams from 4 municipalities of Parana and São Paulo states. Samples stations were defined along each stream. The evaluated physicalchemical parameters were water temperature, dissolved oxygen, $\mathrm{pH}$, turbidity, ammonium, total phosphate, iron, water hardness and chlorine. Physical and chemical analysis used a field colorimetric assay kit. Microbiological analysis of water used pour plate technique with Agar and MacConkey culture media. A protocol of rapid habitat evaluation was used for environmental analysis. The water quality showed some parameters to be out of Brazilian legal limits established for Class 2 water stream. The results indicate that the water stream may cause human health harm and even damage to the freshwater and aquatic communities. The results showed different levels of anthropic interference and correlations between water quality parameters.

KEYWORDS: Water resources; Water quality; Rapid habitat evaluation; Environmental management.

DOI: $10.18554 /$ rbcti.v4i3.3633 


\section{INTRODUÇÃO}

Além de estar cada vez mais escassa em algumas áreas e regiões brasileiras, a água está se tornando em um elemento que não pode ser usado para a maioria dos usos humanos devido à contaminação causada pelo lançamento de efluentes domiciliares, industriais e hospitalares in natura nos corpos d'água (WHO, 2017; ANA, 2018).

Desde longa data, o crescimento populacional e o uso excessivo da água têm destacado o papel do homem como agente transformador e responsável por significativas perdas na integridade de mananciais (MACHADO, 2003; TOGORO, 2006; ANA, 2018).

Embora haja um gerenciamento notável da bacia hidrográfica do rio Paranapanema, tanto na vertente paulista como paranaense, verifica-se o foco dirigido para os tributários de maior porte além do próprio rio Paranapanema. Assim, a situação local dos pequenos mananciais não é avaliada ou mesmo monitorada (CBH NORTE PIONEIRO, 2019). Esta situação é comum a maioria dos planos dos comitês de bacia hidrográfica $(\mathrm{CBH})$ no Brasil.

As microbacias são reflexo da ocupação do seu entorno sendo comum a interferência antrópica, destacando-se o lançamento de esgotos, rejeitos industriais, poluentes provenientes das atividades agrícolas e a retirada da mata ciliar, entre outros (CASTELLO BRANCO JR et al., 2008; TUCCI, 2008; SUGA; TANAKA, 2013; ANA, 2018).

Embora haja instrumentos legais, o cenário de interferência ilegal é comum, estimulando a perpetuação de prática rotineira e ilegal em vários municípios brasileiros de pequeno porte (COSTA, 2005; ANA, 2018). Nestas situações, não há o tratamento do seu esgoto doméstico, havendo o lançamento in natura em cursos d'água de pequeno e médio porte, ainda na área urbana do município (SILVA; SANTOS; LEAL, 2016; ANA, 2018). Mesmo havendo a poluição local de recursos hídricos, não haverá o impacto em cursos d'água de grande porte devido ao seu volume de água (BASSOI; GUAZELLI, 2004). O monitoramento destes grandes mananciais pelo poder público comprova a qualidade de suas águas (ANA, 2018).

O presente trabalho tem por objetivo realizar o diagnóstico ambiental de alguns cursos d'água no Norte Pioneiro do Paraná e no Alto Paranapanema paulista de forma a verificar a situação da qualidade de suas águas diante do enquadramento legal e também a influência das atividades humanas na qualidade de cursos d'água de diferentes municípios pertencentes à bacia hidrográfica do Paranapanema.

\section{MATERIAL E MÉTODOS}

\section{Mapeamento dos cursos d'água}

O estudo foi realizado em 7 mananciais em municípios distintos, a saber, o Ribeirão da Aldeia (3,5 Km de extensão) e o Rio Jundiaí (trecho de 1,3 Km de extensão), dois tributários do Rio das Cinzas, respectivamente, nos municípios de Santo Antônio da Platina e Jundiaí do Sul, ambos no Norte Pioneiro do Estado do Paraná enquanto o terceiro curso d’água foi o Ribeirão Lageado (3,5 Km de extensão), tributário do Rio Fartura no município de Fartura, no oeste do Estado de São Paulo. Estes 3 cursos d'água participam da Bacia Hidrográfica do Alto Paranapamena. Em Ipaussu, também no oeste paulista, foram avaliados 4 mananciais; os córregos São Luís, Bela Vista e Santa Hermínia e o lago municipal. Todos tributários da bacia hidrográfica do Médio Paranapanema. 
Foi feito o mapeamento de cada curso d'água utilizando-se o software Google Earth®. Foram demarcadas estações de coleta de água ao longo de cada manancial.

Em Santo Antônio da Platina - PR, a primeira estação de coleta (EC1) no Ribeirão da Aldeia encontra-se próxima à sua nascente. A segunda estação (EC2), a cerca de 2,8 $\mathrm{km}$ de distância da $E C 1$, está em área urbana. A estação de coleta 3 (EC3), a cerca de 704 $m$ à juzante da $E C 2$, também em área urbana mas próxima a sua foz, antes do encontro com o ribeirão Boi Pintado (Figura 1A).

Figura 1. Extensão avaliada (linha azul) dos 3 cursos d'água e estações de coleta (EC) para análise física, química, microbiológica e avaliação ecológica rápida. A: Ribeirão da Aldeia, em Santo de Santo Antônio da Platina - PR; B: Rio Jundiaí, em Jundiaí do Sul - PR e, C: Ribeirão Lageado, em Fartura - SP

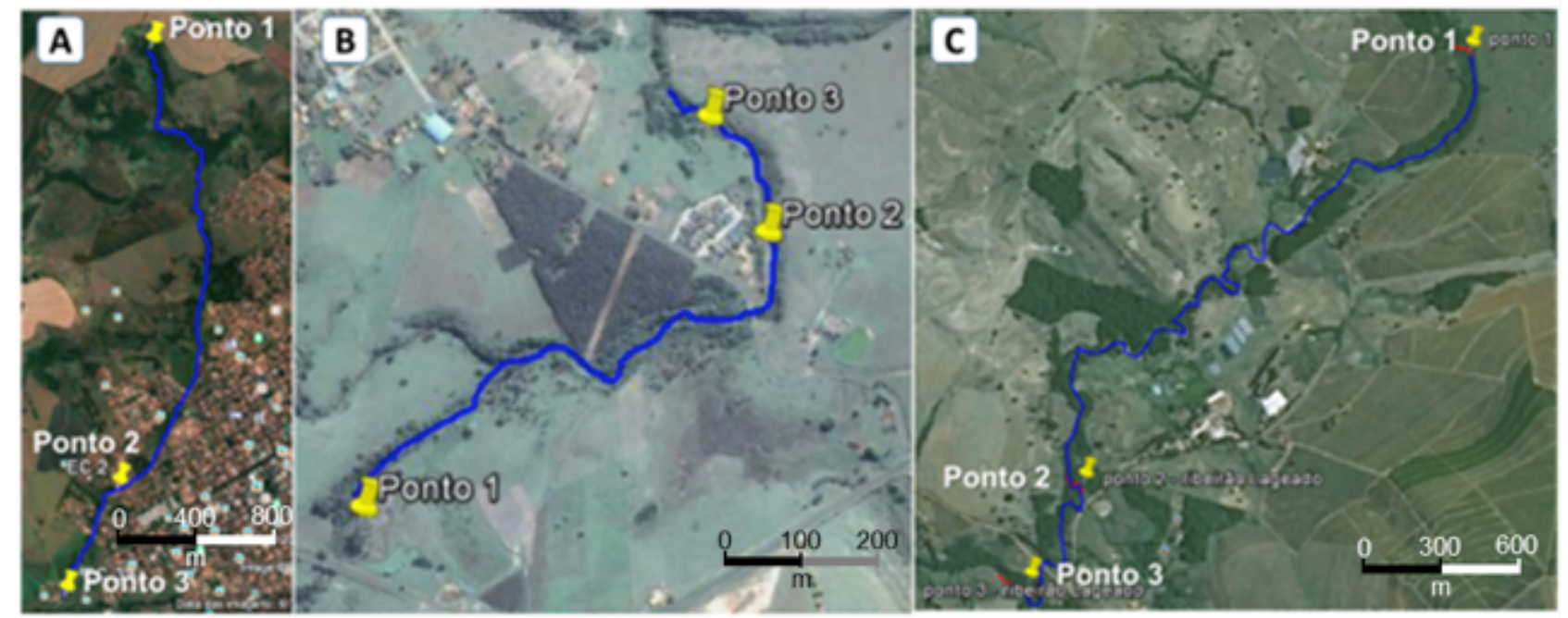

Fonte: Google Earth®

Em Jundiaí do Sul - PR, a EC1, no rio Jundiaí, está em área não habitada enquanto a EC2 foi demarcada em área urbana, próxima à vila Conjunto Osório, poucos metros antes do ponto de lançamento do esgoto. A EC3 foi demarcada $250 \mathrm{~m}$ à juzante da EC2 (Figura 1B).

Em Fartura - SP, a EC1 no Ribeirão Lageado está em trecho fortemente encachoeirado. A EC2, distante cerca de $2,7 \mathrm{Km}$ à juzante da $\mathrm{EC} 1$, está em área de remanso e, a terceira (EC3), 650 m à juzante da estação 2 (Figura 1C).

Ipaussu - SP

A Figura 2 apresenta as 7 estações de coleta em Ipaussu - SP. Foram demarcadas duas EC no córrego São Luís, uma em sua nascente (EC1) e outra em trecho intermediário (EC2). Este córrego forma o lago municipal onde uma única EC (3) foi demarcada.

O córrego Bela Vista nasce na zona urbana e a cruza completamente. A EC4 está em sua nascente, após área de brejo; a EC5, intermediária, e a EC6 ainda em zona urbana.

Uma única estação de coleta (EC7) foi demarcada no córrego Santa Hermínia, também na zona urbana. Este córrego é tributário do córrego Bela Vista.

Todos os mananciais de Ipaussu são tributários da bacia do Médio Paranapanema. 
Figura 2. Mapa da zona urbana de Ipaussu - SP com as 7 estações de coleta demarcadas.

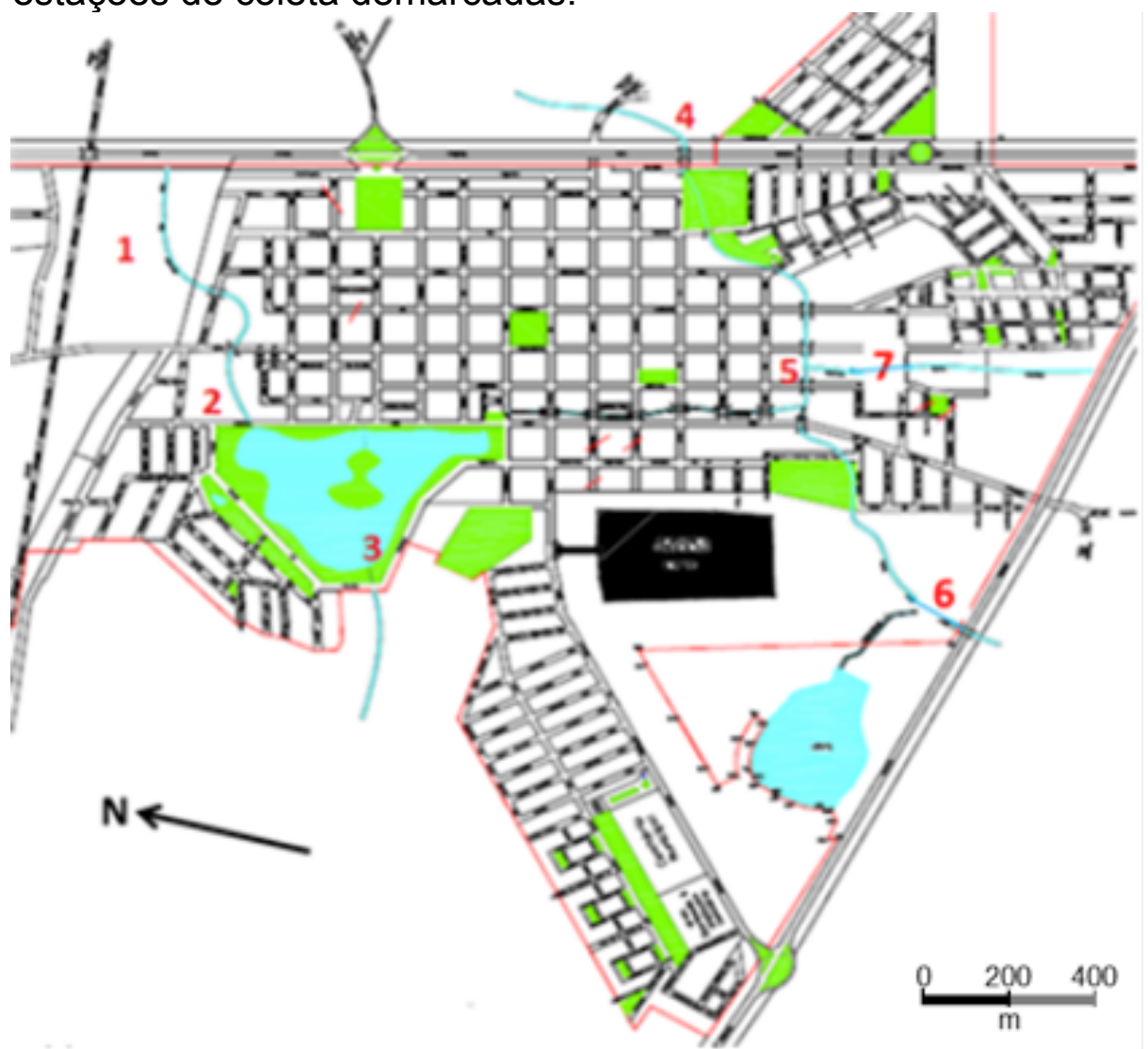

Fonte: Acervo Prefeitura Municipal de Ipaussu - SP

\section{Coleta de amostras d'água}

As amostras da água $(300 \mathrm{~mL})$ foram coletadas nas EC na região central do leito, na zona sub superficial de maior correnteza, direcionando-se a boca do frasco coletor contra a correnteza, não deixando bolhas de ar dentro da garrafa coletora (CETESB, 2011).

\section{Análise Física e Química}

As análises físicas e químicas foram realizadas a campo com o auxílio de kit Alphakit ${ }^{\circledR}$ para determinação de 9 parâmetros: temperatura, oxigênio dissolvido (OD), dureza, amônia, ferro, fosfato, $\mathrm{pH}$, turbidez e cloreto. As análises foram baseadas em critérios colorimétricos por ocasião das coletas de água, seguindo-se o protocolo de operação do fabricante do kit. A temperatura foi aferida diretamente no corpo d'água com termômetro portátil e a turbidez, com disco de Secchi modificado Alphakit® . 2007).

Em cada EC foi calculada a vazão pelo método do flutuador (PALHARES et al.,

\section{Análise Microbiológica}

As amostras de água foram etiquetadas e mantidas no escuro até o processamento no laboratório. A semeadura foi feita pela técnica de disseminação ("Pour Plate"), onde 
alíquota de $1 \mathrm{~mL}$ dos $300 \mathrm{ml}$ da amostra da água era transferida para placa de Petri vazia. Em seguida, $20 \mathrm{~mL}$ de meio de cultura fundido e refrigerado $\left(45^{\circ} \mathrm{C}\right)$ eram adicionados. A homogeneização era obtida por meio de movimentos circulares suaves (VERMELHO et al., 2006). Foram utilizados os meios de cultura Agar-Nutriente e Agar MacConkey. As placas semeadas, em triplicatas, foram encubadas a $37^{\circ} \mathrm{C}$ por 48 horas para leitura de eventual crescimento bacteriano. A contagem foi feita por unidades formadoras de colônias (ufc).

\section{Análise Ambiental}

A análise da influência antrópica sobre cada curso d'água foi feita pelo método de Avaliação Ecológica Rápida aplicando-se o protocolo adaptado de Callisto e colaboradores (2002) em extensão de aproximadamente 100 m em cada Estação de Coleta.

\section{Análise Estatística}

Devido ao volume de dados, optou-se pela análise de componente principal (ACP) com o auxílio dos softwares EXCEL $®$ e XLSTAT® além do uso da correlação de Pearson entre as variáveis dos parâmetros de qualidade da água.

\section{RESULTADOS E DISCUSSÃO}

\section{Análise Física e Química}

Os resultados obtidos quanto aos parâmetros físicos, químicos e microbiológicos para os mananciais avaliados são apresentados na Tabela 1 (cf. Apêndice). Também constam os limites legais estabelecidos pela resolução CONAMA 357/2005 para cursos d'água doce classe 2 .

Os resultados são abordados sob duas perspectivas, uma com foco nos aspectos legais da legislação brasileira para os cursos d'água doce classe 2, a qual se enquadram os mananciais avaliados (SÃO PAULO, 1976, 2009; PARANÁ, 1991; CONAMA, 2005, 2011) e, a segunda abordagem, sob o foco da análise por componentes principais.

No contexto legal, tem-se que alguns parâmetros foram verificados dentro dos limites legais em todas as estações de coleta (EC), de todos os mananciais, como turbidez, amônia e cloreto (Tabela 1). Outros, como pH, fosfato, oxigênio dissolvido (OD) e ferro, foram verificados dentro dos limites legais em algumas EC e em desacordo em outras.

Assim, o parâmetro pH foi verificado em desacordo legal em Ipaussu - SP, próximo às nascentes dos córregos São Luís e Bela Vista. No primeiro córrego, a EC está em área com elevada antropização enquanto que, a EC 4, no córrego Bela Vista, fica logo após uma grande área de brejo o que pode explicar a acidez de suas águas (Tabela 1).

Para Miranda e colaboradores (2009), o pH também pode ter variações devido às descargas de efluentes domésticos e outros lançamentos. Percebe-se que, tanto ao longo do Ribeirão da Aldeia como do Rio Jundiaí, embora dentro dos limites legais, o pH foi aumentando em direção à foz. Esta variação pode estar relacionada ao lançamento de matéria orgânica posteriormente comprovada pela análise microbiológica.

Ainda, no córrego Bela Vista, o OD esteve sempre abaixo do limite mínimo definido em lei comprometendo a manutenção de vida aquática aeróbica. Dois dos fatores que mais influenciam a concentração de OD na água são temperatura e matéria orgânica. Salientase a ocorrência de descarga orgânica, comprovada pela análise microbiológica, e 
colaborando assim, para os baixos níveis de OD uma vez que a depuração da carga orgânica do esgoto consome OD (VON SPERLING, 2007; NUVOLARI, 2011).

Continuando no município de Ipaussu - SP, o parâmetro fosfato foi verificado acima do limite máximo, previsto em lei, em todos os mananciais lóticos (Tabela 1) assim como em todas as EC dos ribeirões da Aldeia e Lageado, respectivamente em Santo Antônio da Platina - PR e em Fartura - SP. Neste segundo manancial, a concentração de fosfato variou de 7,5 a 10 vezes acima do limite definido em lei.

Apesar do fosfato não apresentar problemas de ordem sanitária nas águas de abastecimento, é um elemento indispensável para o crescimento de algas tanto quanto o nitrogênio. Assim, em elevadas concentrações, ambos podem conduzir ao processo de eutrofização tanto em ambientes lóticos quanto lênticos além de contribuir para a redução dos teores de OD (BRAGA et al., 2005; SARDINHA et al., 2008).

A presença elevada de fosfato pode ser explicada pela descarga de efluentes domésticos e de criações animais, principalmente detergentes e fezes (NIETO, 2005). Os detergentes quando incorporados à água levam a formação de espumas em águas sob agitação. Este quadro de formação de espuma foi verificado diversas vezes.

No Ribeirão Lageado, em Fartura - SP, um aspecto relevante na análise de fosfato é a ocorrência de uma granja de suinocultura com um plantel de cerca de 1.500 animais na margem à montante da EC2 (Figura 1C). A granja, na época, ainda instalando um sistema de tratamento de esgoto anaeróbico baseado em bags desidratadores de lodo associado a incineração lançava o esgoto da criação em lagoa adjacente ao Ribeirão Lageado. A proximidade da lagoa ao corpo d'água e o cenário verificado sugerem que esta deságue no ribeirão explicando o aumento da concentração de fosfato em cerca de $33 \%$ entre as EC1 e EC2. A redução da concentração de fosfato de 1,0 para 0,75 ppm entre a EC2 e EC3 pode ser explicada pela contribuição de tributários aumentando sua vazão em cerca de $46 \%$ entre as EC2 e EC3 (Tabela 1). A ocorrência de algas filamentosas, típicas de ambientes eutrofizados, confirmavam a elevada concentração de fosfato a partir da EC2.

Outro aspecto a ser considerado na análise de fosfato é a possível incorporação, aérea e por lixiviação do solo, uma vez que a região do estudo é eminentemente agropastoril e assim, a participação de adubos e defensivos é potencialmente alta. A mata ciliar, pouco presente, colabora para a fácil incorporação de material via lixiviação (BRAGA et al., 2005; NIETO, 2005; DONADIO; GALBIATTI; PAULA, 2005).

Quanto ao parâmetro ferro, os valores verificados acima dos limites legais pode dever-se ao solo da região caracterizado por mosaico, do tipo podzolizado (rico em ferro) (OLIVEIRA; SCHMIDT; FREITAS, 2004). Apesar do sabor adstringente e coloração avermelhada à água, decorrente da sua precipitação, o ferro não representa risco sanitário. No entanto, o ferro em concentrações elevadas interfere na disponibilidade de cloro nas estações de tratamento de água (NIETO, 2005).

Não existem limites legais para os parâmetros temperatura da água e dureza. Quanto à temperatura, o que existe é a regulamentação quanto ao lançamento de efluentes não alterar a temperatura natural dos cursos d'água receptores (CONAMA, 2005). Estes parâmetros serão analisados quando da abordagem por componentes principais.

\section{Análise Microbiológica}

O meio de cultura Agar Base é um meio não seletivo utilizado para cultivo de amostras para exames bacteriológicos e isolamento de microrganismos, enquanto que 0 
Agar MacConkey é seletivo para bactérias Gram negativas, incluindo fermentadoras de glicose como as enterobactérias (VERMELHO et al., 2006).

Os resultados obtidos revelaram contaminação por lançamento de esgoto em diversas situações (Tabela 1).

No Ribeirão da Aldeia, em Santo Antônio da Platina - PR, não houve crescimento algum na EC1, em qualquer meio de cultura. A ausência de coliformes totais na EC1 deve estar relacionada ao fato desta EC estar em área rural e isenta de ações antrópicas.

No entanto, nas demais amostras do Ribeirão da Aldeia e em todas as EC do ribeirão Lageado, em Fartura - SP, houve tamanho crescimento bacteriano que não permitiu contagem alguma já após 24 horas de incubação em ambos meios de cultura (Tabela 1). Assim, pode-se inferir que antes mesmo da EC2, o Ribeirão da Aldeia recebe esgoto doméstico com grande carga de coliformes totais. Tanto a EC2 quanto a EC3 encontram-se em áreas urbanizadas onde já era conhecido o lançamento de esgoto. Em Fartura - SP, toda a extensão do Ribeirão Lageado mostrou-se contaminada por esgoto (Tabela 1).

Os procedimentos realizados, no presente trabalho, não permitem a revelação de coliformes termotolerantes, parâmetro com valor limite estipulado pela Resolução CONAMA 357/05. No entanto, os termotolerantes pertencem a um subgrupo dos coliformes totais revelados pela análise da água no presente trabalho.

Quanto ao Rio Jundiaí, em Jundiaí do Sul - PR, foi possível quantificar as ufc de coliformes totais nas três EC (Tabela 1). Considerando que os coliformes termotolerantes, definidos em lei, no limite legal de $200 \mathrm{ufc} / \mathrm{mL}$ se constituem em um subconjunto dos coliformes totais, tem-se que, se o número de ufc de coliformes totais é menor que o limite de 200 ufc/ 100mL, conclui-se que o número de ufc de termotolerantes será menor ainda. Desta forma, apesar de se confirmar o lançamento de esgoto doméstico nas águas do Rio Jundiaí, suas águas ainda atendem ao parâmetro definido em lei. Esta situação pode dever-se não apenas ao volume de esgoto lançado mas também à vazão do manancial.

Em Ipaussu - SP, houve contaminação em todos os mananciais sendo verificado o não atendimento legal nos córregos S. Luís, Bela Vista e St. Hermínia (Tabela 1).

A quantidade de ufc verificada torna essas situações um sério problema de saúde pública para os municípios, especificamente por haver a real possibilidade de crianças e adultos caírem em seu leito, além das situações de enchentes onde suas águas transbordam chegando a inundar as casas ao entorno.

\section{Análise Ambiental}

A Tabela 2 (cf. Apêndice) apresenta os resultados obtidos pela aplicação do protocolo de Avaliação Ecológica Rápida (PAER) nos mananciais avaliados.

O protocolo de avaliação ecológica rápida (PAER) é utilizado como ferramenta baseada em qualificações visuais que agrega atributos de caráter físico do habitat e parâmetros biológicos possibilitando a caracterização do estado do manancial (CALLISTO et al., 2002). O protocolo utilizado é composto por 22 parâmetros distribuídos em 2 quadros. O primeiro busca avaliar as características do trecho e níveis de impacto ambiental decorrente de atividades antrópicas. O segundo busca avaliar a condição do habitat e o nível de conservação natural. A pontuação final reflete o nível de integridade ambiental ou de preservação encontrada nos trechos avaliados ou de impacto antrópico.

A somatória parcial ou total representa um valor que pode ser comparado no tempo e no espaço, seja no mesmo curso d’água ou comparando-se vários cursos d’água. 
Quanto maior a pontuação, maior será o estado de preservação e menor a influência antrópica. Valores de somatória total entre 0 e 40 pontos caracterizam trechos com elevada influência antrópica enquanto valores entre 41 e 60 indicam trechos já alterados mas com influência antrópica moderada e, trechos com valores de somatória igual ou maior que 61 indicam regiões naturais sem influência antrópica (CALLISTO et al., 2002).

A somatória de todos os valores das EC do mesmo curso d'água permite uma comparação do estado geral dos mananciais. Assim, levando-se em consideração as respectivas somatórias de cada corpo d'água, tem-se que os mananciais de Ipaussu/ SP se destacam como aqueles onde há maior influência antrópica. Em ordem decrescente de influência antrópica tem-se; o lago municipal (36 pontos) seguindo-se dos córregos Santa Hermínia (40 pontos), São Luís (95 pontos) e Bela Vista (131 pontos).

O Ribeirão Lageado, em Fartura - SP, é o manancial com menor influência antrópica (205 pontos), seguido pelo Ribeirão da Aldeia (200 pontos), em Santo Antônio da Platina PR e pelo Rio Jundiaí (158 pontos), em Jundiaí do Sul - PR.

A avaliação ambiental de cada curso d'água revelou situações distintas como por exemplo; desde uma condição natural à juzante das áreas urbanizadas dos Ribeirões da Aldeia, em Santo Antônio da Platina - PR, e Lageado, em Fartura - SP, passando para uma condição de crescente interferência antrópica (Tabela 2). Esta influência antrópica é representada não só pela crescente redução da mata ciliar e erosão crescente de suas margens mas também pelo lançamento de esgoto doméstico e lixo.

O Rio Jundiaí, em Jundiaí do Sul - PR, revelou moderada influência antrópica ao longo de todo o trecho avaliado.

Em Ipaussu - SP, o PAER revelou situações de elevada e moderada influência antrópica como por exemplo, a nascente do córrego Bela Vista (EC1) situada na área urbana com grande alteração da situação primária. O mesmo cenário de influência antrópica verificou-se no lago municipal (EC3), no início e trecho intermediário do córrego Bela Vista (EC4 e EC5) e no córrego Santa Hermínia (EC7) (Tabela 2).

Os resultados obtidos permitiram verificar alterações nos mananciais e no seu entorno tais como assoreamentos, redução de mata ciliar, lançamento de efluentes e depósito de resíduos domésticos e da construção civil às suas margens. Este tipo de verificação é própria da aplicação dos protocolos de avaliação ecológica rápida (TOGORO, 2006; RODRIGUES; CASTRO; MALAFAIA, 2010; FRANÇA; RODRIGUES; MALAFAIA, 2013). O impacto antrópico sobre os ecossistemas aquáticos é um dos responsáveis pela deterioração da qualidade ambiental de bacias hidrográficas (CALLISTO et al., 2002; FIGUEIREDO et al., 2007).

Os resultados obtidos, no presente trabalho, permitem corroborar os relatos de diversos autores sobre o uso desta ferramenta para o diagnóstico e monitoramento de ambientes lóticos e lênticos (CALLISTO et al., 2002; TOGORO, 2006; RODRIGUES; MALAFAIA; CASTRO, 2008; RODRIGUES; CASTRO; MALAFAIA, 2010; BRITO et al., 2011; FIRMINO; MALAFAIA; RODRIGUES, 2011; VARGAS; FERREIRA JUNIOR, 2012; FRANÇA; RODRIGUES; MALAFAIA, 2013).

\section{Análise de Componentes Principais}

Embora a análise de componentes principais (ACP) não seja utilizada para a verificação de enquadramento legal dos cursos d'água, seu uso para análises ecológicas é útil por extrair informações de grande quantidade de dados com o mínimo de perda de informações, reduzindo a complexidade das interrelações entre um grande número de 
variáveis em componentes principais que expliquem a maior parte da variabilidade dos dados originais (RIBAS; VIEIRA, 2011; ROCHA; PEREIRA, 2016). A primeira componente explica o máximo da variabilidade total dos dados enquanto a segunda, explica o máximo da variabilidade dos dados restantes, não correlacionados com a primeira e assim sucessivamente (GUEDES et al., 2012).

A Tabela 3 (cf. Apêndice) apresenta tanto os autovalores das componentes principais como a variância explicada e acumulada em cada componente. As três primeiras componentes explicaram cerca de $72 \%$ da variância total dos dados. Embora não exista um critério consensual sobre o número de fatores que devem ser extraídos na análise, segundo alguns autores, sugere-se a extração dos fatores com autovalor maior que 1,0 enquanto outros, sugerem que o número de componentes que representem $60 \%$ da variância acumulada, refletiriam uma ideia aceitável da variância original (MINGOTI, 2005; HAIR et al., 2007; NONATO et al., 2007; FIGUEIREDO FILHO; SILVA JUNIOR, 2010; ROCHA; PEREIRA, 2016; ROCHA; SILVA; FREITAS, 2016). Desta forma, as 3 primeiras componentes atendem aos critérios de todos os autores acima citados.

Assim, tem-se que a componente 1 (F1) foi constituída pelas variáveis dureza, cloreto e pH enquanto a componente 2 (F2) foi constituída por fosfato, coliformes e temperatura da água e, por último, a componente 3 (F3) constituída pelas variáveis amônia e turbidez.

A Figura 3 apresenta o mapa perceptual da ACP das componentes F1 e F2 que respondem por cerca de $54,0 \%$ da variabilidade dos dados originais juntamente com as EC plotadas. A análise das componentes F1 e F3 não foi efetuada por responderem por apenas $48 \%$ da variação dos dados obtidos. A análise das componentes principais F1 e F2 permite algumas inferências. A primeira é que situações onde a vazão é aumentada, todos os demais parâmetros estarão diminuídos com exceção do parâmetro Ferro. Analogamente, amostras com maiores valores de OD, turbidez, temperatura da água e dureza tenderiam a ter menores valores de fosfato, coliformes, $\mathrm{pH}$ e cloreto.

Segundo Rocha e Pereira (2016), o ângulo agudo entre os vetores das variáveis permite inferir haver elevada correlação. Assim, pode-se inferir elevada correlação entre turbidez-OD, entre pH-cloreto, entre cloreto-amônia e entre dureza-amônia (Figura 3).

Embora o mapa perceptual (Figura 3) sugira uma correlação dos dados obtidos entre turbidez e OD, o mesmo não se verificou na correlação de Pearson ( $P=0,007)$. No entanto, considerando-se que a turbidez influencia na passagem dos raios solares nos corpos d'água e assim, interfere na disponibilidade de luz para a fotossíntese, a relação entre estas variáveis é possível mas não confirmada nas situações dos cursos d'água avaliados. $O$ mesmo cenário se verificou para as correlações indicadas, pelo mapa perceptual, para cloreto-amônia $(P=-0,1003)$ e entre dureza-amônia $(P=-0,0221)$. Coeficientes de correlação de Pearson iguais ou maiores que 0,5 indicam forte correlação entre as variáveis enquanto valores entre 0,3 e 0,49 indicam correlação moderada entre as variáveis.

Já a correlação entre pH e cloreto também foi evidenciada pela correlação de Pearson $(P=0,5965)$. É conhecida a interferência do $\mathrm{pH}$ na determinação da presença de cloretos na água bruta além da relação entre $\mathrm{pH}$ e disponibilidade de nitrogênio na água (VON SPERLING, 2007; CRUZ; CLAIN, 2010). 
Figura 3. Mapa perceptual da Análise de Componentes Principais (ACP) das componentes F1 e F2 que respondem por cerca de $54,0 \%$ da variabilidade dos dados originais. Vetores (linhas cheias) das variáveis (parâmetros da qualidade da água): vazão $(\mathrm{Q})$, ferro $(\mathrm{Fe})$, temperatura d'água $\left(\mathrm{T}^{\circ} \mathrm{C}\right)$, oxigênio dissolvido $(\mathrm{OD})$, amônia $\left(\mathrm{NH}_{3}\right)$, cloreto $\left(\mathrm{Cl}^{-}\right)$e fosfato $\left(\mathrm{PO}_{4}\right)$. Pontos (Estações de Coleta)

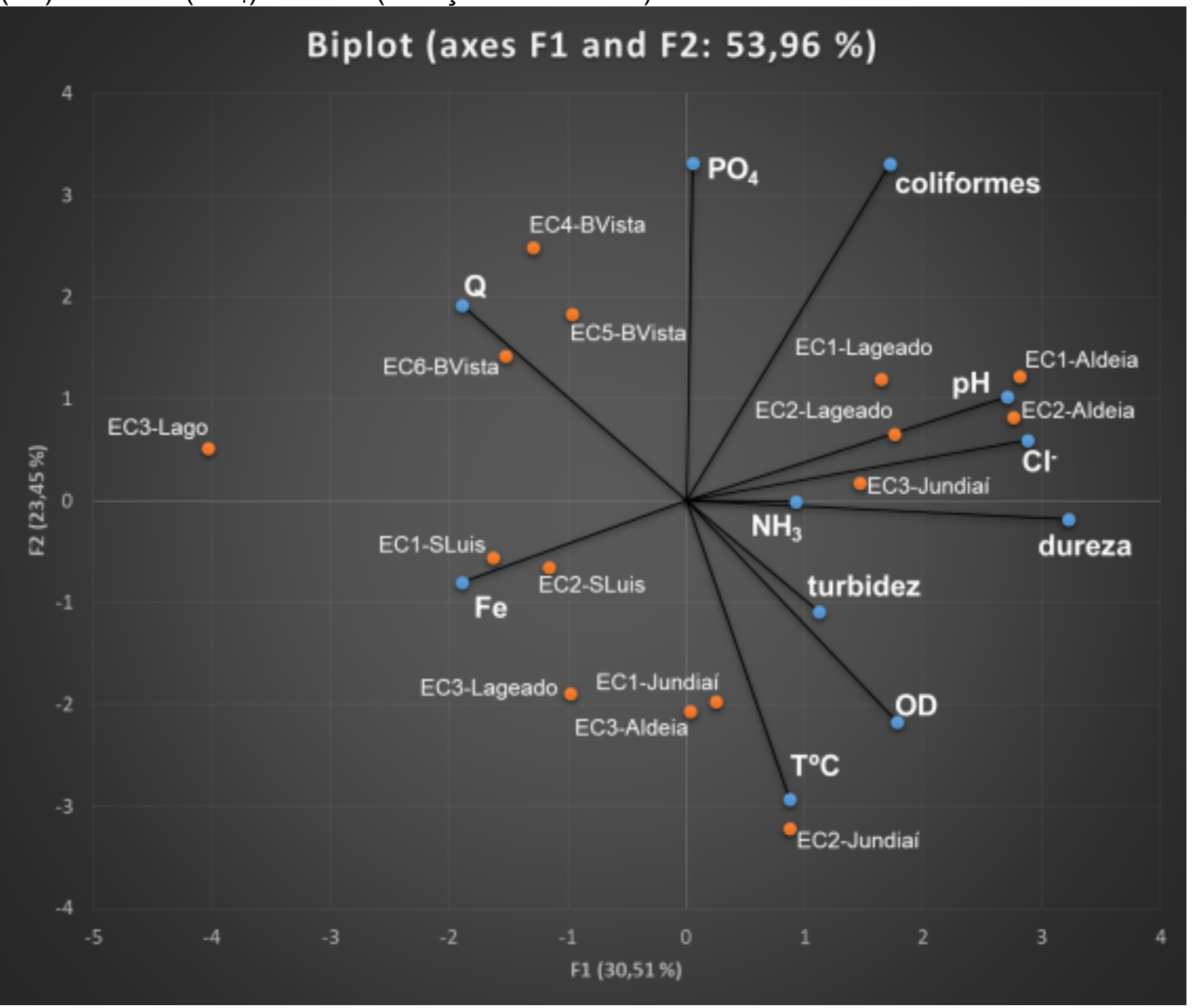

Outra correlação indicada pelo mapa perceptual e confirmada pela correlação de Pearson $(P=0,5552)$ foi quanto ao fosfato e a presença de coliformes totais. A influência da disponibilidade de fosfato para o crescimento bacteriano é notória sendo corroborada pelos dados obtidos (VERMELHO et al., 2006; VON SPERLING, 2007).

Considerando-se ainda que variáveis altamente correlacionadas tendem a ficar próximas e na mesma direção, pode-se inferir correlações entre as variáveis amônia-pHcloreto; dureza-turbidez-OD-temperatura d'água e; fosfato-coliformes. Algumas destas correlações já foram comentadas anteriormente. Acrescente-se ainda a relação da temperatura da água com a solubilidade dos gases na água e assim, influenciando na disponibilidade de OD (VON SPERLING, 2007). Salienta-se que a relação entre temperatura d'água e OD também confirmada pela correlação de Pearson $(P=0,3839)$. 


\section{CONCLUSÕES}

Os resultados obtidos, no presente trabalho, demonstram que não apenas o processo de urbanização mas também o modelo de uso da área rural trouxeram vários impactos para os recursos hídricos.

Comprovou-se que a qualidade dos cursos d'água menores está comprometida, impactando os locais e as populações humanas que dependem destes recursos hídricos e também as respectivas comunidades aquáticas. Essa situação não é evidenciada nos relatórios de comitês de bacias hidrográficas devido à metodologia empregada.

Considerando-se a corresponsabilidade do poder público, do setor privado e da sociedade civil na gestão de seus próprios recursos hídricos, os resultados obtidos demonstram ser relevante também a avaliação local dos pequenos e médios cursos d'água para ações efetivas de controle e gestão local sejam melhor planejadas e executadas.

\section{REFERÊNCIAS}

ANA - Agência Nacional de Águas (Brasil). Conjuntura dos recursos hídricos no Brasil 2018: informe anual. Agência Nacional de Águas. Brasília: ANA, 2018.

BASSOI, L. J.; GUAZELLI, M. R. Controle Ambiental da Água. In: PHILLIPI JR., A; ROMÉRIO, M. A.; BRUNA, G. C. Curso de Gestão Ambiental. Barueri: Manole, 2004.

BRAGA, B. et al. Introdução a Engenharia Ambiental: o desafio do desenvolvimento sustentável. 2. ed. São Paulo: Pearson, 2005.

BRITO, M.T.S. et al. Protocolos de avaliação ambiental rápida de açudes do Semiárido: Adaptações regionais e um estudo de caso. In: MESSIAS, A.S.; FEITOSA, M.C.A. (Org.) A influência das mudanças climáticas sobre os recursos hídricos. 6 . ed. Recife: UNICAP, 2011.

CALLISTO, M. et al. Aplicação de um protocolo de avaliação rápida da diversidade de habitats em atividade de ensino e pesquisa (MG- RJ). Acta Limnologica Brasiliensia, v. 14, n. 1, p. 91-98, 2002.

CASTELLO BRANCO JR., A. et al. Avaliação das condições sanitárias e ambientais da sub-bacia do córrego Barbosa no município de Marília/SP. Revista do Instituto Adolfo Lutz, v. 67, n. 3, p.183-189, 2008.

CBH NORTE PIONEIRO. Comitê das bacias hidrográficas do Rio das Cinzas, Itararé e Paranapanema I e II), 2019. Disponível em:

http://www.paranapanema.org/index.php?option=com_content\&view=article\&id=50\&ltemid =62 Acesso em 24 jan. 2019.

CETESB - Companhia Ambiental do Estado de São Paulo. Guia nacional de coleta e preservação de amostras: água, sedimento, comunidades aquáticas e efluentes líquidos. Brasília, DF, 2011. 
CONAMA - CONSELHO NACIONAL DE MEIO AMBIENTE. Resolução $n^{\circ} \mathbf{3 5 7}$, de 17 de março de 2005: dispõe sobre a classificação dos corpos de água e diretrizes ambientais para o seu enquadramento, bem como estabelece as condições e padrões de lançamento de efluentes, e dá outras providências. Brasília, DF, 2005. Disponível em:

http://www2.mma.gov.br/port/conama/legiabre.cfm?codlegi=459. Acesso em: 24 jan. 2019.

CONAMA - CONSELHO ANCIONAL DE MEIO AMBIENTE. Resolução $n^{\circ} \mathbf{4 3 0}$, de 13 de maio de 2011: Dispõe sobre as condições e padrões de lançamento de efluentes, complementa e altera a Resolução ${ }^{\circ} 357$, de 17 de março de 2005, do Conselho Nacional do Meio Ambiente-CONAMA. Brasília, DF, 2011. Disponível em: < http://www2.mma.gov.br/port/conama/legiabre.cfm?codlegi=646 >. Acesso em 24.jan 2019

COSTA, E.J. Impactos ambientais no córrego Palmital no município de Urutaí GO. Enciclopédia Bioesfera, n. 1, p. 1 - 23, 2005.

CRUZ, J.N.; CLAIN, A.F. A Interferência do pH na Análise de Cloreto pelo Método de Mohr. Revista Eletrônica TECCEN, Vassouras, v. 3, n. 3, p. 29-44, 2010.

DONADIO, N. M. M.; GALBIATTI, J. A.; PAULA, R. C. Qualidade da água de nascentes com diferentes usos do solo na bacia hidrográfica do córrego Rico, São Paulo, Brasil. Engenharia Agrícola, v. 24, n. 1, p. 115-125, 2005.

FIGUEIREDO, M.C.B. et al. Avaliação da vulnerabilidade ambiental de reservatórios à eutrofização. Engenharia Sanitária e Ambiental, v.12, n. 4, p. 399-409, 2007.

FIGUEIREDO FILHO, D. B.; SILVA JÚNIOR, J. A. Visão além do alcance: uma introdução à análise fatorial. Opinião Pública, v. 16, n. 1, p. 160-185, 2010.

FIRMINO, P.F.; MALAFAIA, G.; RODRIGUES, A. S. L. Diagnóstico da integridade ambiental de trechos de rios localizados no município de Ipameri, sudoeste do estado de Goiás, através de um protocolo de avaliação rápida. Brazilian Journal of Aquatic Science and Technology v. 15, n. 2, p. 1-12, 2011.

FRANÇA, L.O.; RODRIGUES, A.S.L.; MALAFAIA, G. Diagnóstico ambiental do córrego do Açude, Orizona -GO por meio de um protocolo de avaliação rápida de rios. Revista Tropica: Ciências Agrárias e Biológicas, v. 7, n. 1, p. 33-44, 2013.

GUEDES, H. A. S. et al. Aplicação da análise estatística multivariada no estudo da qualidade da água do Rio Pomba, MG. Revista Brasileira de Engenharia Agrícola e Ambiental, v. 16, n. 5, p. 558-563, 2012.

HAIR, J. J. F. et al. Análise multivariada de dados. 5. ed. Porto Alegre: Bookman, 2007.

MACHADO, C.J.S. Recursos hídricos e cidadania no Brasil: limites, alternativas e desafios. Ambiente \& Sociedade, v. 4, n. 2, p. 120-136, 2003. 
MINGOTI, S.A. Análise de dados através de métodos de estatística multivariada: uma abordagem aplicada. Belo Horizonte: Editora UFMG, 2005.

MIRANDA, R.G. et al. Qualidade dos recursos hídricos da Amazônia-Rio Tapajós: avaliação de caso em relação aos elementos químicos e parâmetros físicoquímicos. Revista Ambiente \& Água - An Interdisciplinary Journal of Applied Science, v.4, n. 2, p. 75-92, 2009.

NIETO, R. Tratamento de efluentes líquidos industriais e domésticos. São Paulo: CETESB, 2005.

NONATO, E. A. et al. Tratamento estatístico dos parâmetros da qualidade das águas da bacia do Alto Curso do Rio das Velhas. Revista Química Nova, v.30, n.4, p.797-804, 2007.

NUVOLARI A. Esgoto Sanitário. Coleta, transporte, tratamento e reuso agrícola. São Paulo: Editora Blucher, 2011.

OLIVEIRA, A. D.; SCHIMIDT, G.; FREITAS, D.M. Avaliação de teor de ferro em águas subterrâneas de alguns poços tubulares, no plano diretor de Palmas/TO. Congreso Interamericano de Ingenieria Sanitaria y Ambiental, San Juan, 2004.

PALHARES, J.C.P. ET AL. Medição da vazão em rios pelo método do flutuador. Comunic. Técnico 455, Embrapa, Concórdia, SC. 2007.

PARANÁ, Portaria SUREHMA No 006/91, de 19 de setembro de 1991. Enquadramento dos cursos d'água do Estado do Paraná: Bacia do Rio das Cinzas. Disponível em: < http://www.recursoshidricos.pr.gov.br/arquivos/File/enquadramento-b-cinzas.pdf $>$. Acesso em 24 jan.2019.

RIBAS, J.R.; VIEIRA, P.R.C. Análise multivariada com o uso do SPSS. Rio de Janeiro: Ciência Moderna, 2011.

ROCHA, C.H.B.; PEREIRA, A.M. Análise multivariada para seleção de parâmetros de monitoramento em manancial de Juiz de Fora, Minas Gerais. Revista Ambiente \& Água, vol. 11, n. 1, p. 176-187, 2016.

ROCHA, C.H.B.; SILVA, T.M.; FREITAS, F.A. Processos condicionantes de alterações em variáveis limnológicas: uma abordagem estatística na Represa de São Pedro, Juiz de Fora (MG). Engenharia Sanitária e Ambiental, v. 21, n. 1, p. 131-138, 2016.

RODRIGUES, A.S.L.; MALAFAIA, G; CASTRO, P.T.A. Avaliação ambiental de trechos de rios na região de ouro Preto-MG através de um protocolo de avaliação rápida. Revista de Estudos Ambientais, v. 10, n. 1, p. 74-83, 2008.

RODRIGUES, A.S.L.; CASTRO, P.T.A.; MALAFAIA, G. Utilização de protocolos de avaliação rápida de rios como instrumentos complementares na gestão de bacias 
hidrográficas envolvendo aspectos da geomorfologia fluvial: uma breve discussão. Enciclopédia Biosfera, v.6, n.11, p.1-9, 2010.

SÃO PAULO, Decreto $\mathbf{n}^{\circ} \mathbf{8 . 4 6 8}$, de 8 de setembro de 1976. Aprova o Regulamento da Lei n. ${ }^{\circ}$ 997, de 31 de maio de 1976, que dispõe sobre a prevenção e o controle da poluição do meio ambiente. São Paulo, SP, 1976. Disponível em: < https://www.al.sp.gov.br/repositorio/legislacao/decreto/1976/decreto-846808.09.1976.html>.Acesso em: 24 jan.2019.

SÃO PAULO, Decreto $n^{\circ}$ 54.487, de 26 de junho de 2009. Atualiza Decreto $n^{\circ} 8468 /$ 1976, sobre a prevenção e o controle da poluição do meio ambiente. São Paulo, SP., 2009. Disponível em:

http://www.al.sp.gov.br/repositorio/legislacao/decreto/2009/decreto\%20n.54.487,\%20de\% 2026.06.2009.htm. Acesso em: 24 jan. 2019.

SARDINHA, D. S. et al. Avaliação da Qualidade da Água e Autodepuração do Ribeirão do Meio, Leme (SP). Engenharia Sanitária e Ambiental, v.13, n. 3, p. 329-338, 2008.

SILVA, P.M.; SANTOS, F.M.; LEAL, A.C. Planejamento Ambiental da Bacia Hidrográfica do Córrego da Olga, UGRHI Pontal do Paranapanema-SP. Sociedade \& Natureza, v. 28, n.3, p. $409-428,2016$

SUGA, C. M.; TANAKA, M. Influence of a forest remnant on macro invertebrate communities in a degraded tropical stream. Hydrobiologia, v. 703, n. 1, p. 203-213, 2013.

TOGORO, E.S. Qualidade da água e integridade biótica: estudo de caso num trecho fluminense do Rio Paraiba do Sul. Tese Doutorado. Rio de Janeiro: Universidade do Estado do Rio de Janeiro. 2006.

TUCCI, C. E. M. Águas urbanas. Estudos avançados, v. 22, n. 63, p. 97-112, 2008.

VARGAS, J.R.A.; FERREIRA JUNIOR, P.D. Aplicação de um protocolo de avaliação rápida na caracterização da qualidade ambiental de duas microbacias do Rio Guandu, Afonso Cláudio, ES. Revista Brasileira de Recursos Hídricos, v. 17, n. 1, p.161-168, 2012.

VERMELHO, A.B. et al. Práticas de Microbiologia, Rio de Janeiro:Guanabara Koogan, 2006.

VON SPERLING, M. Estudos e modelagem da qualidade da água de rios. Princípios do Tratamento Biológico de águas residuárias. DESA/UFMG, v. 7, 2007.

WHO Progress on drinking water, sanitation and hygiene: 2017 update and SDG baselines. Geneva: World Health Organization (WHO) and the United Nations Children's Fund (UNICEF). 
Revista Brasileira de Ciência, Tecnołogia e Inovaçăo

\section{APÊNDICE}

Tabela 1. Resultados verificados quanto aos parâmetros de qualidade de água nas estações de coleta (EC) nos cursos d'água avaliados; Ribeirão da Aldeia (Santo Antônio da Platina - PR), Rio Jundiaí (Jundiaí do Sul/PR), Ribeirão Lageado (Fartura - SP), Córrego São Luís (Ipaussu - SP), Lago municipal (Ipaussu - SP), Córrego Bela Vista (Ipaussu - SP) e Córrego Santa Hermínia (Ipaussu - SP) e padrões de qualidade das águas segundo Resolução Conama $\mathrm{n}^{\circ} 357 / 2005$ para cursos d'água doce classe 2.

\begin{tabular}{|c|c|c|c|c|c|c|c|c|c|c|}
\hline \multirow[b]{2}{*}{ Parâmetro (unidade) } & \multicolumn{3}{|c|}{ Ribeirão da Aldeia } & \multicolumn{3}{|c|}{ Rio Jundiaí } & \multicolumn{3}{|c|}{ Ribeirão Lageado } & \multirow[b]{2}{*}{ Conama 357} \\
\hline & EC 1 & EC 2 & EC 3 & EC 1 & EC 2 & EC 3 & EC 1 & EC 2 & EC 3 & \\
\hline Vazão (L/s) & 14,9 & 18,4 & 38,1 & 210,0 & 283,4 & 283,4 & 185,7 & 188,7 & 275,4 & nd \\
\hline $\mathrm{OD}\left(\mathrm{mg} \mathrm{O}_{2} / \mathrm{L}\right)$ & 7,0 & 6,5 & 8,2 & 6,2 & 5,7 & 9,7 & 7,1 & 6,8 & 7,6 & $\geq 5,0$ \\
\hline Fosfato (mg/L) & 0,75 & 0,75 & 0,75 & 0 & 0 & 0 & 0,75 & 1,0 & 0,75 & $\leq 0,1$ \\
\hline Ferro (mg/L) & 1,0 & 0,5 & 0,25 & 0,25 & 0,50 & 3,0 & 0,25 & $\leq 0,25$ & 0,25 & $\leq 0,3$ \\
\hline Cloreto (mg/ L) & 20 & 37 & 25 & 17 & 15 & 20 & 18,0 & 18,0 & 18,0 & $\leq 250,0$ \\
\hline $\mathrm{pH}$ & 7,0 & 7,5 & 8,0 & 6,0 & 7,0 & 8,0 & 7,5 & 8,0 & 7,75 & $6,0-9,0$ \\
\hline Amônia(mg/ L) & 0,10 & 0,25 & 0,25 & 0,25 & 0,1 & 0,25 & 2,0 & 3,0 & 2,0 & $\leq 3,7(p / p H \leq 7,5)$ \\
\hline Turbidez (ntu) & 50,0 & 100,0 & 50,0 & 100,0 & 100,0 & 75,0 & 50,0 & 50,0 & 50,0 & $\leq 100$ \\
\hline Temperatura água $\left({ }^{\circ} \mathrm{C}\right)$ & 21,0 & 21,0 & 23,0 & 28,0 & 29,0 & 33,0 & 22,0 & 25,0 & 25,0 & nd \\
\hline Dureza (mg/L CaCO $\left.{ }_{2}\right)$ & 104,0 & 95,0 & 118,0 & 60,0 & 65,0 & 56,0 & 80,0 & 60,0 & 80,0 & nd \\
\hline \multirow[t]{2}{*}{ Coliformes totais (ufc) } & 0 & ni & ni & 75 & 94 & 96 & ni & $\mathrm{ni}$ & $\mathrm{ni}$ & $\leq 200 \mathrm{ufc} / 100 \mathrm{~mL}$ \\
\hline & \multicolumn{3}{|c|}{ Córrego São Luís } & Lago & \multicolumn{3}{|c|}{ Córrego Bela Vista } & \multicolumn{2}{|c|}{ Córrego St. Hermínia } & \\
\hline Parâmetro (unidade) & EC 1 & \multicolumn{2}{|c|}{ EC 2} & EC 3 & EC 4 & EC 5 & EC 6 & \multicolumn{2}{|c|}{ EC 7} & Conama 357 \\
\hline Vazão (L/s) & 0,9 & \multicolumn{2}{|c|}{35,1} & -- & -- & -- & 2244,3 & \multicolumn{2}{|c|}{--} & \\
\hline $\mathrm{OD}\left(\mathrm{mg} \mathrm{O}_{2} / \mathrm{L}\right)$ & $>10$ & \multicolumn{2}{|c|}{5,8} & 5,2 & 4,9 & 4,6 & 5,3 & \multicolumn{2}{|c|}{4,4} & $\geq 5,0$ \\
\hline Fosfato (mg/L) & 0 & \multicolumn{2}{|c|}{0,75} & 0 & 0,75 & 0,75 & 0,75 & \multicolumn{2}{|c|}{0,75} & $\leq 0,1$ \\
\hline Ferro (mg/L) & 0,25 & \multicolumn{2}{|c|}{3,0} & 0,25 & 3,0 & 1,0 & 1,0 & \multicolumn{2}{|c|}{1,0} & $\leq 0,3$ \\
\hline Cloreto (mg/ L) & 12,0 & \multicolumn{2}{|c|}{12,0} & 12,0 & 8,0 & 16,0 & 18,0 & \multicolumn{2}{|c|}{8,0} & $\leq 250,0$ \\
\hline $\mathrm{pH}$ & 5,0 & \multicolumn{2}{|c|}{6,25} & 6,75 & 5,0 & 7,5 & 7,0 & \multicolumn{2}{|c|}{6,5} & $6,0-9,0$ \\
\hline Amônia(mg/ L) & 3,0 & \multicolumn{2}{|c|}{0,25} & 0,5 & 0,1 & 0,25 & 0,25 & \multicolumn{2}{|c|}{0,5} & $\leq 3,7(\mathrm{p} / \mathrm{pH} \leq 7,5)$ \\
\hline Turbidez (ntu) & $<50$ & \multicolumn{2}{|c|}{100} & $<50$ & $<50$ & $<50$ & 100 & \multicolumn{2}{|c|}{$<50$} & $\leq 100$ \\
\hline Temperatura água $\left({ }^{\circ} \mathrm{C}\right)$ & 22,0 & \multicolumn{2}{|c|}{22,0} & 22,0 & 22,0 & 21,0 & 22,0 & \multicolumn{2}{|c|}{22,0} & nd \\
\hline Dureza $\left(\mathrm{mg} / \mathrm{L} \mathrm{CaCO}_{2}\right)$ & 15,0 & \multicolumn{2}{|c|}{30,0} & 28,0 & 10,0 & 20,0 & 15,0 & \multicolumn{2}{|c|}{18,0} & nd \\
\hline Coliformes totais (ufc) & 0 & & & 49 & 0 & ni & ni & & & $\leq 200 \mathrm{ufc} / 100 \mathrm{~mL}$ \\
\hline
\end{tabular}

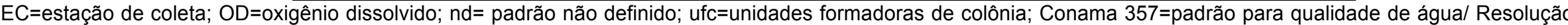
Conama $\mathrm{n}^{\circ} 357 / 2005$ para cursos d'água classe 2; ni=nº incontável de colônias após $24 \mathrm{~h}$ de plaqueamento.

\begin{tabular}{|l|l|l|l|l|l|l|}
\hline Rev. Bras. Cien., Tec. e Inov. & Uberaba, MG & v. 4 & n. 3 & p. 228-243 & out./dez. 2019 & ISSN 2359-4748 \\
\hline
\end{tabular} 
Tabela 2. Pontuação resultante da aplicação do Protocolo de Avaliação Ecológica Rápida (PAER) proposto por Callisto et al.(2002) nas Estações de Coleta (EC) dos cursos d'água avaliados e classificação da influência antrópica.

\begin{tabular}{|c|c|c|c|c|c|c|c|c|c|}
\hline \multirow[t]{2}{*}{ Manancial } & \multirow[t]{2}{*}{ Município/Estado } & \multicolumn{7}{|c|}{ Estações de Coleta } & \multirow{2}{*}{$\begin{array}{l}\text { Influência } \\
\text { Antrópica }\end{array}$} \\
\hline & & EC1 & EC2 & EC3 & EC4 & EC5 & EC6 & EC7 & \\
\hline Ribeirão da Aldeia & S. Ant. Platina/PR & 95 & 60 & 45 & - & - & - & - & natural-moderada-moderada \\
\hline Rio Jundiaí & Jundiaí do Sul/PR & 52 & 51 & 55 & - & - & - & - & moderada \\
\hline Ribeirão Lageado & Fartura/PR & 90 & 53 & 62 & - & - & - & - & natural-moderada-natural \\
\hline Córrego São Luiz & Ipaussu/SP & 40 & 55 & - & - & - & - & - & elevada.-moderada \\
\hline Lago municipal & Ipaussu/SP & - & - & 36 & - & - & - & - & Elevada \\
\hline Córrego Bela Vista & Ipaussu/SP & - & - & - & 39 & 37 & 55 & - & elevada-elevada-moderada \\
\hline Córrego S. Hermínia & Ipaussu/SP & - & - & - & - & - & - & 40 & elevada \\
\hline
\end{tabular}

Nota: Natural= sem influência antrópica; elevada=elevada influência antrópica; Moderada=moderada influência antrópica

Tabela 3. Análise de Componentes Principais (CP) com autovalores das componentes principais, variabilidade expressa por CP e acumulada.

\begin{tabular}{|c|c|c|c|c|c|c|c|c|c|c|c|}
\hline $\mathrm{CP}$ & F1 & F2 & F3 & F4 & F5 & F6 & F7 & F8 & F9 & F10 & F11 \\
\hline Autovalores & 3,356 & 2,579 & 1,966 & 0,895 & 0,687 & 0,546 & 0,472 & 0,207 & 0,119 & 0,105 & 0,067 \\
\hline Variabilidade (\%) & 30,510 & 23,447 & 17,877 & 8,136 & 6,246 & 4,964 & 4,292 & 1,879 & 1,083 & 0,956 & 0,611 \\
\hline Acumulativo (\%) & 30,510 & 53,957 & 71,833 & 79,969 & 86,216 & 91,179 & 95,471 & 97,350 & 98,434 & 99,389 & 100,000 \\
\hline
\end{tabular}

Recebido em: 21/03/2019

Aprovado em: 26/06/2019 